Smith, H. Williams' (1959). .J. gen. Microbiol. 21, 622-630

\title{
The Bacteriophages of Clostridium perfringens
}

\author{
By H. WILLIAMS SMI'TH
}

The Animal Health Trust, Farm Livestock Research Centre, Stock, Essex

SUMMARY: A search has been made for phages active on Clostridium perfringens, types A, B, C, D, E, and F. Twelve of 49 type A strains, 10 of 31 type B strains, 10 of 26 type $C$ strains and none of either 38 type $D, 5$ type $E$ or 3 type $F$ strains were lysogenic. The 'temperate' phages obtained from these lysogenic cultures, together with similar phages obtained from crude material, such as sewage, were only active on strains of the same type as the lysogenic culture from which they were isolated; some of them were very host-specific. It was possible to induce partial lysis in lysogenic strains by ultraviolet radiation, nitrogen mustard and mercaptoacetic acid.

Other phages isolated from crude material resembled the 'virulent' phages of aerobic bacteria. These phages lysed strains belonging to types $A, B, C, D$, and F.

Despite a long search for phages that would lyse them, a high proportion of the strains of Clostridium perfringens examined remained insusceptible to all the phages isolated. A close relationship between phage susceptibility and colonial morphology was noted. Smooth and rough strains were usually phage susceptible; mucoid strains were usually phage-resistant.

Bacteriophages which lyse anaerobic bacteria have been studied much less than those active on aerobic bacteria. Recently, however, the position has improved as far as phages active on Clostridium perfringens are concerned, principally by the studies of Guelin and her collaborators (Elford, Guelin, Hotchin \& Challice, 1953; Guelin, 1949, 1950, 1955; Guelin \& Kreguer, 1950; Kreguer, Guelin \& Le Bris, 1947). Although these workers have commented upon the selective action of some of the phages which they isolated from crude materials, such as polluted water, little published information exists as to the specificity of phages for the different types of C. perfringens. Also, no work appears to have been published upon the existence and behaviour of lysogenic cultures of these bacteria. The present studies were undertaken principally in order to obtain information on these two points.

\section{METHODS}

Clostridium perfringens cultures. The studies were mainly concerned with 152 strains. Of these, 49 belonged to type $A, 31$ to type $B, 26$ to type $C$, 38 to type D, 5 to type $\mathrm{E}$ and 3 to type F. Twelve of the type A strains and the 3 type $F$ strains had been responsible for outbreaks of food poisoning; the remainder had been isolated from man and a variety of domestic animals. The majority of the B, C, D and E strains had originated from outbreaks of disease in sheep. Freshly isolated strains were also used from time to time for different purposes; apart from the fact that they produced lecithinase, no information was sought as to what type they belonged.

Solid medium. The solid medium used for all the studies consisted of blood 
agar base (Oxoid), 40 g.; bacto-casitone (Difco), 10 g.; yeast extract (Oxoid), $2 \cdot 0 \mathrm{~g}$.; distilled water to $1000 \mathrm{ml}$. This was found to be the most suitable after studying a variety of media. Some ingredients were definitely disadvantageous. The addition of glucose, for example, yielded bacterial growth which, although more prolific, possessed an uneven surface which made plaques difficult to discern.

Liquid media. Although several different liquid media were used in searching for phage in crude material, cooked meat medium (Oxoid) in 1 oz. screwcapped bottles was used for all other purposes.

Phosphate buffer. This consisted of $\mathrm{KH}_{2} \mathrm{PO}_{4}, 3.4 \mathrm{~g}$.; $\mathrm{Na}_{2} \mathrm{HPO}_{4}, 6.0 \mathrm{~g}$.; distilled water, $1000 \mathrm{ml}$. Its $\mathrm{pH}$ was $7 \cdot 0$.

Search for lysogenic cultures. Modifications of the cross-culture technique (Fisk, 1942) were used to identify lysogenic strains. Cultures were studied in batches of 20, various combinations being employed until most of the 152 strains had been tested against each other. The 20 strains were grown in cooked meat medium for $18 \mathrm{hr}$. at $37^{\circ}$; each was then used as an indicator strain by spreading 5 drops $(0.1 \mathrm{ml}$.) of the culture over the surface of a dry plate of solid medium. When dry, the remaining 19 cultures were 'spotted' on to it. The plates were incubated for $18 \mathrm{hr}$. at $37^{\circ}$ in an atmosphere of $95 \%(\mathrm{v} / \mathrm{v})$ hydrogen $+5 \%(\mathrm{v} / \mathrm{v})$ carbon dioxide. Phage action was revealed by the presence of zones of lysis or by discrete plaques.'The interpretation was sometimes complicated by the fact that many of the strains produced inhibitory substances for each other. These substances were distinguished from phage by their failure to reproduce in cultures of the indicator strain.

Several modifications of the technique described above were also used, e.g. liquid cultures of different ages and incubation of the tests at different temperatures from $37^{\circ}$ to $28^{\circ}$. Different media were also used and a useful expedient was to add nitrogen mustard to the cooked meat medium because it was found to partially 'induce' phage production in lysogenic cultures of Clostridium perfringens. Supernatant fluids of liquid cultures after : centrifugation were also examined as well as cultures in which the bacteria had been killed either by heating to $58^{\circ}$ for $30 \mathrm{~min}$. or by chloroform (Fredericq, 1950). On other occasions, cultures were incubated, before testing, with a strain known to be susceptible to phage previously isolated. On one occasion oxytetracycline-resistant cultures were used as indicator strains growing on a medium containing oxytetracycline hydrochloride, $1 \mu \mathrm{g} . / \mathrm{ml}$ :

The isolation of phages from crude material. Several methods were used in attempts to isolate phages from material such as sewage, pond and river water, faeces of healthy animals and intestinal contents of sheep dead from Clostridium perfringens type $\mathrm{D}$ infection; no one method showed itself to be uniformly the best. Crude material was added to various liquid media and incubated for 6-24 hr. at temperatures between $28^{\circ}$ and $37^{\circ}$. Sometimes the material was heated to $58^{\circ}$ for $30 \mathrm{~min}$. before incubation and sometimes streptomycin sulphate $(20 \mu \mathrm{g} . / \mathrm{ml}$.), was added after heating. On other occasions, cultures, particularly those which had not at that time been found to be susceptible to the phages already isolated, were also added to the 
medium before incubation. After incubation, the cultures were centrifuged and the supernatant fluids, before and after heating to $58^{\circ}$ for $30 \mathrm{~min}$. or treating with chloroform, were spotted on to plates spread with different indicator cultures of $C$. perfringens. :The plates were incubated at $28^{\circ}$ or $37^{\circ}$ anaerobically for $18 \mathrm{hr}$. and then examined for phage action. Sometimes the crude material was centrifuged and filtered through a Seitz E.K. sterilizing pad before it was incubated with the selected cultures in liquid media.

Purification and propagation of phages. When phage action was noted the lytic area was picked and mixed, in different dilutions, with a meat broth culture of the susceptible strain; the mixtures were then spread over the surface of a plate of solid medium and incubated anaerobically at $37^{\circ}$ for $18 \mathrm{hr}$. (The word 'strain' is used throughout with reference to bacteria and not to phages.) A discrete plaque was picked and replated with the propagating strain. This process was repeated twice. Finally, a discrete plaque with some of the surrounding bacterial growth was picked into meat broth and incubated at $37^{\circ}$. until lysis occurred. Usually, more of the susceptible strain was then added and incubation continued. Clearing of the culture was conveniently followed by comparison with a control culture inoculated with the propagating strain only. Finally; the lytic material was centrifuged, filtered through a Seitz E.K. sterilizing pad and tested for bacterial sterility. By this process it was usually possible to obtained relatively high titred phage preparations (C.T.D. of $10^{-3}-10^{-6}$ ), the potency of the preparation being only slightly reduced by filtration. Known lysogenic strains were never used as propagating strains.

Titration of phage preparations. A meat broth culture of the propagating strain of Clostridium perfringens was spread evenly over the dried surface of a plate of solid medium, allowed to dry and then spotted with one drop (c. $1 / 150 \mathrm{ml}$.) of each tenfold dilution of the phage preparation in phosphate buffer. The plate was then incubated anaerobically for $18 \mathrm{hr}$. The highest dilution which produced semi-confluent plaques was chosen as the critical test dilution (c.T.D.), i.e. the dilution to be used routinely in comparing the activity of phages against different strains of $C$. perfringens. For this purpose, meat broth cultures of strains under test were spread over plates of solid media in the manner described above and the phages in c.T.D. strength on their original indicators spotted on to them before incubating at $37^{\circ}$ for $18 \mathrm{hr}$. The particular definition of C.T.D. used in these studies was selected because it was unlikely to be confused with the activity of the antibacterial substances described above which some of the phage preparations contained.

Phage counts were carried out in a similar manner as the phage titrations, the technique being a modification of the Miles \& Misra (1938) method for counting bacteria. When the phage content of lysogenic cultures was being determined, the cultures were first destroyed by heating to $58^{\circ}$ for $30 \mathrm{~min}$. or treating with chloroform; the few spores that remained did not complicate the phage-counting procedure.

Preparation of phage-resistant strains of Clostridium perfringens. Secondary colonies appearing in areas of complete lysis were picked and purified by three 
serial single colony isolations. They were then tested on solid medium to confirm their complete resistance to the undiluted phage preparation. Attempts to produce phage-resistant strains were sometimes made by prolonged incubation of a susceptible culture and phage in meat broth medium. and then examining colonies obtained by plating on solid medium.

Cross resistance tests. These were performed by a modification of Bail's (1923) original method. Variants resistant to each of the phages were isolated from a single bacterial strain. The phages were then titrated against each of the variants.

Bacterial counts. These were carried out by the method of Miles \& Misra (1938).

Determination of colonial morphology. Meat broth cultures were streaked on to plates of the solid medium and their colonial morphology was then determined according to the method of Stevens (1935).

\section{RESULTS}

The incidence of lysogenic strains. among different types of Clostridium perfringens. The incidence of demonstrably lysogenic strains is shown in Table 1. Phages isolated from different strains have been assumed to be identical if they resembled each other in host range, plaque morphology, resistance to heat and chloroform, and behaved similarly in cross-resistance tests.

Table 1. The incidence of lysogenic cultures of Clostridium perfringens

$\begin{array}{ccc}\begin{array}{c}\text { Type of } \\ \text { C. perfringens }\end{array} & \begin{array}{c}\text { No. of strains } \\ \text { examined }\end{array} & \text { No. lysogenic } \\ \text { A } & 49 & 12 \\ \text { B } & 31 & 10 \\ \text { C } & 26 & 10\end{array}$

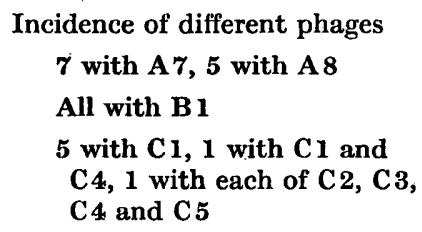

The susceptibility of strains of Clostridium perfringens to phages isolated from crude material and from lysogenic cultures. Table 2 shows.the response of strains of $C$. perfringens to the phages isolated from the above lysogenic cultures as well as to phages isolated from crude material. The latter were of two kinds: six which lysed some type $\mathbf{A}$ strains only (and were therefore designated $\mathbf{A}$ phages, numbers 1-6), and 30 which also lysed strains of other types: These 30 were designated group phages. All the group phages had the same host range which was very wide although they differed in plaque morphology. On the other hand, all the $\mathrm{A}$ phages and also those isolated from type $\mathrm{C}$ strains were highly specific, some being active against only one strain of $C$. perfringens (e.g. C.1 in Table 2). The only $B$ phage isolated attacked 18 of 31 type $B$ strains tested; 10 of the insusceptible 13 type $B$ strains were demonstrably lysogenic with this phage.

No strain of Clostridium perfringens could be lysogenized by the group phages. Some type A strains, however, could be lysogenized by the A phages 
1-6 isolated from crude material, a fact which indicated that these phages had probably originated from lysogenic $C$. perfringens present in that material.

The relationship between phage susceptibility and colonial morphology. Apart from a few strains that were probably intermediate in character, those that had been phage typed could be classified, on the basis of colonial morphology, into mucoid, smooth and rough. The results of comparing colonial morphology and susceptibility to the group phages is illustrated in Table 3. With few exceptions, the smooth and rough strains were susceptible to these phages and the mucoid strains were resistant. 'The exceptions were mainly type $\mathrm{C}$

Table 2. The susceptibility of strains of Clostridium perfringens to phages

\begin{tabular}{|c|c|c|c|c|c|c|c|c|c|c|c|c|c|c|c|c|}
\hline \multirow{3}{*}{$\begin{array}{l}\text { Type of } \\
\text { C. per- } \\
\text { fringens }\end{array}$} & \multirow{3}{*}{$\begin{array}{c}\text { No. } \\
\text { of } \\
\text { strains }\end{array}$} & \multicolumn{15}{|c|}{ Susceptibility to } \\
\hline & & \multirow{2}{*}{$\begin{array}{r}\text { Group } \\
\text { phages }\end{array}$} & \multicolumn{8}{|c|}{ A phages } & \multirow{2}{*}{$\begin{array}{c}\text { B } \\
\text { phage } \\
1\end{array}$} & \multicolumn{5}{|c|}{ C f hages } \\
\hline & & & 1 & $\mathbf{2}$ & $\mathbf{8}$ & 4 & 5 & 6 & 7 & 8 & & 1 & 2 & 3 & 4 & 5 \\
\hline \multirow[t]{11}{*}{$\mathbf{A}$} & 5 & + & + & - & - & - & + & - & - & - & - & - & - & - & - & - \\
\hline & 2 & + & + & - & + & + & - & - & - & - & - & - & - & - & - & - \\
\hline & 1 & + & - & + & + & - & - & - & - & - & - & - & - & - & - & - \\
\hline & 1 & + & - & - & - & - & + & - & + & - & - & - & - & - & - & - \\
\hline & 1 & + & + & - & - & + & - & - & - & + & - & - & - & - & - & - \\
\hline & 1 & - & - & - & - & - & - & + & - & - & - & - & - & - & - & - \\
\hline & 2 & - & - & - & - & + & - & - & - & - & - & - & - & - & - & - \\
\hline & 2 & - & - & + & - & - & - & - & - & - & - & - & - & - & - & - \\
\hline & 1 & - & - & - & - & - & + & - & - & - & - & - & - & - & - & - \\
\hline & 1 & + & - & - & - & - & - & - & - & - & - & - & - & - & - & - \\
\hline & 32 & - & - & - & - & - & - & - & - & - & - & - & - & - & - & - \\
\hline \multirow[t]{2}{*}{ B } & 18 & + & - & - & - & - & - & - & - & - & + & - & - & - & - & - \\
\hline & 13 & - & - & - & - & - & - & - & - & - & - & - & - & - & - & - \\
\hline \multirow[t]{7}{*}{$\mathbf{C}$} & 1 & + & - & - & - & - & - & - & - & - & - & + & + & + & + & - \\
\hline & 2 & + & - & - & - & - & - & - & - & - & - & - & + & + & + & - \\
\hline & 4 & + & - & - & - & - & - & - & - & - & - & - & + & + & - & - \\
\hline & 1 & + & - & - & - & - & - & - & - & - & - & - & + & - & - & + \\
\hline & 1 & - & - & - & - & - & - & - & - & - & - & - & - & - & - & + \\
\hline & 8 & + & - & - & - & - & - & - & - & - & - & - & - & - & - & - \\
\hline & 9 & - & - & - & - & - & - & - & - & - & - & - & - & - & - & - \\
\hline \multirow[t]{2}{*}{ D } & 6 & + & - & - & - & - & - & - & - & - & - & - & - & - & - & - \\
\hline & 32 & - & - & - & - & - & - & - & - & - & - & - & - & - & - & - \\
\hline $\mathbf{E}$ & 5 & - & - & - & - & - & - & - & - & - & - & - & - & - & - & - \\
\hline \multirow[t]{2}{*}{$\mathbf{F}$} & 1 & + & - & - & - & - & - & - & - & - & - & - & - & - & - & - \\
\hline & 2 & - & - & - & - & - & - & - & - & - & - & - & - & - & - & - \\
\hline
\end{tabular}

$+=$ lysis $;-=$ no action.

The group phages and $A 1,2,3,4,5$ and 6 were isolated from crude material; the remainder were isolated from lysogenic cultures.

strains, 4 of the 14 mucoid strains referred to in Table 3 being phage susceptible; the phages, however, produced much smaller plaques on these 4 strains than on smooth strains.

A similar situation existed amongst freshly isolated strains. Of 12 strains tested immediately after their primary isolation from faeces of farm animals and human beings, 11 were mucoid and phage-resistant and one was smooth and phage-susceptible. 
The relationship between phage susceptibility and colonial morphology, although definite, was less close in the case of the $A$ and $C$ phages, a few of the 19 mucoid A strains shown in Table 3, for example, being susceptible to the type A phages.

Varying the incubation temperature, the constitution of the culture medium and the density of the bacterial inoculum did not render the mucoid strains susceptible to phage action.

\section{Table 3. The relationship between colonial morphology and susceptibility} to the group phages

\begin{tabular}{|c|c|c|c|}
\hline $\begin{array}{l}\text { Type of } \\
\text { C. perfringens }\end{array}$ & $\begin{array}{l}\text { Colonial } \\
\text { morphology }\end{array}$ & $\begin{array}{l}\text { No. of } \\
\text { strains } \\
\text { tested }\end{array}$ & $\begin{array}{l}\text { No. } \\
\text { susceptible } \\
\text { to group } \\
\text { phages }\end{array}$ \\
\hline A & $\begin{array}{l}\text { Mucoid } \\
\text { Smooth } \\
\text { Rough }\end{array}$ & $\begin{array}{r}19 \\
6 \\
1\end{array}$ & $\begin{array}{l}\mathbf{0} \\
6 \\
1\end{array}$ \\
\hline $\mathbf{B}$ & $\begin{array}{l}\text { Mucoid } \\
\text { Smooth } \\
\text { Rough }\end{array}$ & $\begin{array}{r}13 \\
15 \\
3\end{array}$ & $\begin{array}{r}0 \\
15 \\
2\end{array}$ \\
\hline C & $\begin{array}{l}\text { Mucoid } \\
\text { Smooth } \\
\text { Rough }\end{array}$ & $\begin{array}{r}14 \\
4 \\
1\end{array}$ & $\begin{array}{l}4 \\
4 \\
1\end{array}$ \\
\hline D & $\begin{array}{l}\text { Mucoid } \\
\text { Smooth } \\
\text { Rough }\end{array}$ & $\begin{array}{r}11 \\
3 \\
2\end{array}$ & $\begin{array}{l}\mathbf{0} \\
\mathbf{3} \\
\mathbf{2}\end{array}$ \\
\hline
\end{tabular}

Variation in colonial morphology and phage susceptibility. Several of the strains referred to above yielded both mucoid and smooth colonies when cultured on the solid media, one or other of these two variants being predominant in each strain; the smooth variants were susceptible to the group phages but the mucoid ones were not. During 10 serial single colony subcultures on the solid medium these mucoid and smooth variants bred true as regards colonial morphology and phage susceptibility. However, continuous subculture of the smooth variants, as well as of strains initially classified as smooth, in meat broth instead of on the solid medium, often gave rise to mucoid variants which were resistant to the group phages. As passage proceeded, these variants became more predominant and then, not infrequently, the only kind found in the meat broth. Passage of mucoid strains in meat broth gave rise only infrequently to smooth phage-sensitive variants. With only one of 10 mucoid strains did this form of variation occur. The smooth variants arose in small numbers only in cultures of this strain, remained for several passages and then disappeared.

The relationship between phage susceptibility and colonial morphology was particularly interesting among the 31 Clostridium perfringens type B strains studied. Of these, 18 were susceptible to both the group phages and phage $B 1$ and 13 were resistant to them. None of the 18 susceptible strains but the majority of the 13 resistant strains were demonstrably lysogenic, the 
phage with which they were infected being, in all cases; B1. Consequently, it was thought at first that this lysogenic relationship was responsible for the 13 strains being resistant to the group phages as well as to B1. The fact that resistant variants prepared by lysogenizing susceptible strains with B1 were also resistant to the group phages supported this view. However, these resistant variants and the 13 resistant strains were all noted to possess a mucoid colonial morphology, whereas the 18 susceptible strains were either smooth or rough. Furthermore, serial subculture of the susceptible strains in meat broth often gave rise to mucoid variants which were resistant to the group phages but still susceptible to $\mathrm{B} 1$. It was probable, therefore, that the 13 strains were resistant to the group phages because they were mucoid and not because they were lysogenic with B 1 .

Characteristics of lysogenic cultures of Clostridium perfringens. The number of phage particles found in lysogenic cultures varied from strain to strain; it was usually small. The ratio between the numbers of viable bacteria and phage particles in a meat broth culture of a strain lysogenic with $A 1$ was in the region of 100,000:1, with $\mathrm{C} 1$ was 20,000:1 and with B1 was 1000:1.

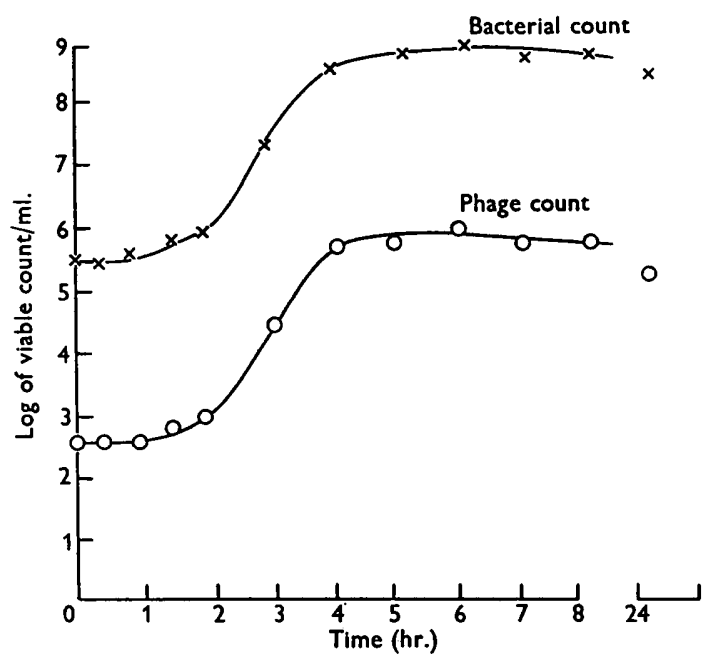

Fig. 1 The numbers of viable bacteria and phage particles in a growing culture of Clostridium perfringens, type B.

A typical growth curve of the bacteria and phage particles in a culture latently. infected with $\mathrm{B} 1$ is shown in Fig. 1. The number of viable phage particles present at any time was directly related to the bacterial count.

Table 4 indicates that lysis could be partially inducted in lysogenic cultures by ultraviolet (u.v.) radiation, nitrogen mustard and to a much lesser extent by mercaptoacetic acid. The latter two substances were simply added to the meat broth medium which the lysogenic cultures were being incubated; with u.v. irradiation, lysogenic bacteria suspended in distilled water were exposed and then incubated in meat broth medium. Treatment with urethane, 


\section{C. perfringens phages}

colehicine or hydrogen peroxide had no effect on the liberation of phage particles by lysogenic cultures.

Apart from differences in host range and plaque morphology, some of the phages carried by lysogenic strains differed markedly from each other in regard to resistance to heat and chloroform. For example, phage A 7 resisted heating to $58^{\circ}$ and chloroform treatment but phage A8 was killed by both. Phage B 1 was killed by chloroform but not by heat treatment; the reverse was true with phage $\mathrm{C} 1$. These phages, too, differed in the time they remained viable at $3^{\circ}$.

Table 4. The induction of lysis in lysogenic cultures of Clostridium perfringens

\begin{tabular}{lccc} 
& \multicolumn{3}{c}{$\begin{array}{c}\text { Inducing factor* for cultures latently } \\
\text { infected with phage }\end{array}$} \\
\cline { 2 - 4 }$\quad$ A7 & B 1 & C1 \\
Substance & 20 & 100 & 20 \\
Nitraviolet radiation & 100 & 40 & 10,000 \\
& $(0 \cdot 04)$ & $(0.01)$ & $(0 \cdot 01)$ \\
Mercaptoacetic acid & 1 & 5 & 10 \\
& $(0 \cdot 5-8)$ & $(4)$ & $(4)$
\end{tabular}

* This was the factor by which the number of phage particles liberated by a lysogenic culture under the influence of an inducing substance was greater than that liberated, at any period, by a control culture.

The figures in parentheses are the concentrations of inducing substance in $\mathrm{mg} . / \mathrm{ml}$. that produced the record-inducing effect.

\section{DISCUSSION}

It.is clear from the present investigation that the host-parasite relationships existing between phages and Clostridium perfringens closely resemble those that apply in the case of the aerobic bacteria. Such variations in plaque morphology and in resistance to heat and chloroform occurring in $C$. perfringens phages have been described in phages of aerobic bacteria. It is apparent, too, that the group phages with their inability to enter into the lysogenic state with bacteria fit the classification 'virulent' as applied to certain phages of aerobic bacteria. The others which were much more specific as regards host range and formed lysogenic cultures with appropriate bacteria resemble the 'temperate' phages that infect aerobic bacteria. The ability of u.v. radiation, nitrogen mustard and mercaptoacetic acid to induce lysis in lysogenic cultures is also a well-known feature of the 'aerobic' phages.

Although it was possible to identify the type of Clostridium perfringens to which some strains belonged by the use of the type-specific phages, such a procedure would probably not be of much practical value because of the large proportion of strains that were insusceptible to the action of all the phages $(61 \cdot 2 \%)$. An exception may be made in the case of type $B$ because all except a few of the strains of this type examined were either susceptible to phage B 1 or could be easily shown to be latently infected with this phage. 
Despite the exhaustive nature of our search for phages, it was surprising that so many strains of Clostridium perfringens remained insusceptible to all the phages isolated. This was undoubtedly associated with the fact that many of these strains were mucoid. The close relationship in the type $\mathbf{B}$ strains between lysogenicity with phage $\mathrm{BI}$ and mucoid colonial morphology is interesting. It is not inconceivable that in nature, infection of susceptible smooth strains with phage B1 may play a part in the evolution of mucoid forms of type $B$ strains.

The relationship between colonial morphology and phage susceptibility, although close, was not complete, a few of the $\mathbf{A}$ phages in particular being active on certain mucoid strains. In view of this, it must be borne in mind that the use of more suitable indicator strains than those employed in the present investigation might reveal many more strains to be lysogenic, a state of affairs that might alter the whole outlook for the phage typing of Clostridium perfringens.

I am grateful to' Mr A. J. Harman and Miss Linda Kelly for their capable technical help and to Dr K. C. Sellers for helpful advice. My thanks are also due to Dr J. J. Bullen, Dr S. T. Cowan, Mr E. C. Hulse, Mr M. O. J. McCarthy, Mr R. S. Roberts, Dr M. Sterre and Mr A. Thomson for providing me with many of the cultures of Clostridium perfringens used in this work.

\section{REFERENCES}

BAIL, O. (1923). Versuche über die Vielheit von Bakteriophagen. Z. ImmunForsch. $38,57$.

Elford, W. J., Guelin, A. M., Hotchin, J. E. \& Challice, C. E. (1953). Le phénomène de la bactériophagie chez les anaérobies. Ann. Inst. Pasteur, 84, 319.

Fisk, R. T. (1942). Studies on staphylococci. I. Occurrence of bacteriophage carriers amongst strains of Staphylococcus aureus. II. Identification of Staphylococcus aureus strains by means of bacteriophage. J. infect. Dis. 71, 153, 161.

FredericQ, P. (1950). Examination of colicine-producing strains for lysogenicity. C.R. Soc. Biol., Paris, 144, 728.

Guelin, A. (1949). Comportement d'un bactériophage actif sur $C l$. relchii. Ann. Inst. Pasteur, 77, 40.

Guelin, A. (1950). Sur la présence du bactériophage perfringens dans les eaux et son rôle dans l'épuration des eaux stagnantes. Ann. Inst. Pasteur, 79, 447.

GuELIN, A. (1955). Isolement et étude des bactériophages actifs sur les anaérobies. Leur rôle dans l'évolution du phlegmon expérimental. Annn. Inst. Pasteur, 88, 289.

Guelin, A. \& Kreguer, A. (1950). Action du bactériophage sur la toxicité des cultures jeunes du $\mathrm{Cl}$. perfringens type A. Ann. Inst. Pasteur, 78, 532.

Kreguer, A., Guelin, A. \& Le Bris, J. (1947). Isolement d'un bactériophage actif sur le Clostridium perfringens type A. Ann. Inst. Pasteur, 73, 1038.

Miles, A. A. \& Misra, S. S. (1938). The estimation of the bactericidal power of the blood. J. Hyg., Camb. 46, 82.

Stevens, F. A. (1935). The dissociation of Clostridium relchii. J. infect. Dis. 57, 275. 